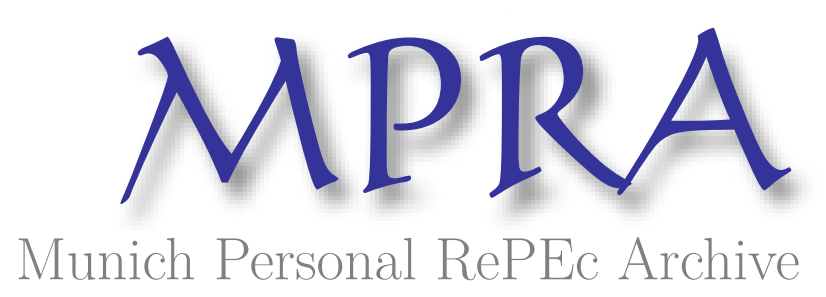

\title{
Natural Selection, Irrationality and Monopolistic Competition
}

Luo, Guo Ying

McMaster University- DeGroote School of Business

May 2009

Online at https://mpra.ub.uni-muenchen.de/15357/

MPRA Paper No. 15357, posted 23 May 2009 17:53 UTC 


\title{
Natural Selection, Irrationality and Monopolistic Competition
}

\author{
Guo Ying Luo ${ }^{1}$ \\ DeGroote School of Business \\ McMaster University
}

\begin{abstract}
This paper builds an evolutionary model of an industry where firms produce differentiated products. Firms have different average cost functions and different demand functions. Firms are assumed to be totally irrational in the sense that firms enter the industry regardless of the existence of profits; firms' outputs are randomly determined rather than generated from profit maximization problems; and firms exit the industry if their wealth is negative. It shows that without purposive profit maximization assumption, monopolistic competition still evolves in the long run. The only long run survivors are those that possess the most efficient technology, face the most favorable market conditions and produce at their profit maximizing outputs. This paper modifies and supports the classic argument for the derivation of monopolistic competition.
\end{abstract}

JEL classification: D21, D43, L10

Keywords: Evolution, Natural Selection, Irrationality, Monopolistic Competition, Survival of the Fittest

\footnotetext{
${ }^{1}$ Correspondent: Guo Ying Luo, Department of Finance and Business Economics, DeGroote School of Business, McMaster University, 1280 Main Street West, Hamilton, Ontario, Canada, L8S 4M4. Tel: (905)525-9140 ext 23983. Email: luogy@mcmaster.ca
} 


\section{Introduction}

The notion of monopolistic competition was invented in responding to the severe limitation in conducting economic analysis using a framework of either pure competition or pure monopoly. Monopolistic competition has elements of both pure competition and pure monopoly. It examines an industry where competing firms produce similar but different commodities. Due to the product differentiation, each firm has a certain degree of monopoly power. This is reflected in firms' downward-slope demand curves. The free entry and exit condition along with firms' profit maximization behavior leads the industry to long-run zero profits. The corresponding firms' outputs are the ones that maximize their respective profits. In other words, they produce at the tangency point where their demand curves are tangent to their respective average cost curves. Chamberlin (1933) and Robinson (1933) both derive this same equilibrium using different techniques. In their derivation of this equilibrium, they both heavily rely on the rationality and purposive profit maximization behavior on firms' part.

However, there are a variety of reasons that firms cannot possibly maximize their profits or profit maximization may not be their objective (see Baumol (1959), Williamson (1964), Simon (1979), Arrow (1986), Andrews (1949), and Cyert and March (1963)).

Without the purposive profit maximization behavior, could monopolistic competition still arrives as a long-run equilibrium? Could the classic argument for the derivation of monopolistic competition still holds?

The early literature (e.g., Alchian (1950), Enke (1951), Friedman (1953)) presents market selection argument to validate profit maximization hypothesis. Alchian (1950) writes "Realized positive profits, not maximum profits, are the mark of success and viability. It does not matter through what process of reasoning or motivation such 
success was achieved. The fact of its accomplishment is sufficient. This is the criterion by which the economic system selects survivors: those who realize positive profits are the survivors; those who suffer losses disappear.". Enke (1951) presents more details on how the market selection works. Enke (1951) says that "In the long run, however, if firms are in active competition with one another rather than constituting a number of isolated monopolies, natural selection will tend to permit the survival of only those firms that either through good luck or great skill have managed, almost or completely, to optimize their position and earn the normal profits necessary for survival. In these instances the economist can make aggregate predictions as if each and every firm knew how to secure maximum long-run profits.". Friedman (1953) also advocates that "The process of natural selection thus helps to validate the hypothesis (of profit maximization) or, rather, given natural selection, acceptance of the hypothesis can be based largely on the judgment that it summarizes appropriately the conditions for survival."

Later, Winter $(1964,1971)$, and Nelson and Winter (1982) further examine this market selection argument in the context of retained earnings dynamics. They found that the retained earnings of profit maximizers will grow fastest and eventually those firms will dominate the market. Nelson and Winter (1982) present a partial equilibrium model where prices are fixed and all firms have access to the same technology; it shows that "as if " profit maximization describe the long run steady state of firms' behavior. Dutta and Radner (1999), and Blume and Easley (2002) examine whether natural selection favors profit maximizing firms in models with added capital market, where firms can grow through retained earnings or through financing in the capital markets. Dutta and Radner (1999) shows that all surviving firms are not profit maximizing firms. Blume and Easley (2002) shows that the market selection favors profit maximizing firms, but the 
long-run behavior of evolutionary market models is not well described by the equilibrium models based on the profit maximization hypothesis.

Luo $(1995,2007)$ present two evolutionary models of industry dynamics, which support the profit maximization hypothesis through the market selection arguments. Furthermore, in both papers, the long-run behavior of the industries is consistent with the one based on the profit maximization hypothesis. The papers basically says that even though firms are not maximizing their profits (their outputs are randomly determined upon their entry to the industry), natural selection selects for the firms that happen to produce at profit maximizing outputs, which in turn promote rational aggregate market outcomes. Specifically, Luo (1995) examines an industry where all firms produce a homogenous commodity. It formally proves that with firms' total irrationality, perfect competition as a long run equilibrium evolves with the "as if " profit maximizers as the only survivors. Luo (2007) obtains similar conclusion in examining a more complex industry structure where firms produce similar but differentiated products. Namely, the monopolistic competition arrives as a long run outcome where only the "as if" profit maximizers survive. Luo (2007) assumes the symmetric demand function and identical average cost function for all firms. However, this paper builds on these models and assumes the non-symmetric demand function and non-identical average cost function for all firms. Specifically, this paper constructs an evolutionary model of an industry where firms produce similar but differentiated products and each firm has its own inherent demand and average cost function. Firms enter the industry sequentially over time. Each firm's output is randomly determined upon its entry and fixed thereafter. If a firm realizes a profit, the profit becomes a part of its wealth. If a firm's wealth is positive at the beginning of a period, the firm will continue to produce its product 
next period; otherwise, the firm exits the industry at the end of that time period. The nonnegative wealth serves as a market selection criterion. This type of modelling strategy completely rules out firms' rationality in their decision of entry to the industry, exit from the industry; and in the determination of the level of their outputs to produce. The paper concludes that with non-symmetric demand function and non-identical average cost function, not all "as if " profit maximizers will survive. The firms producing at their minimum efficient scales will not survive. The only survivors in the long run are the "as if " profit maximizers who possess the most efficient technology and face the most favorable market conditions. In aggregate, monopolistic competition arises in the

long run. This paper modifies and supports the classic argument for the derivation of monopolistic competition. In other words, firms' rationality is not needed in achieving monopolistic competition. In addition, the long run survivors produce at a suboptimal level of output (less than their minimum efficient scales). This is consistent with the empirical findings in the industrial organization literature (see Weiss (1963 and 1976), Scherer (1973), and Pratten (1971)) that a majority of firms are not only small but also small enough so as to operate at a suboptimal level of output (instead of the minimum efficient scale) in most industries.

\section{The Model}

Consider an industry where firms enter sequentially over time, producing a similar but differentiated products. For simplicity, one firm is assumed to enter the industry each time period. The firm that enters at time period $t$, where $t=1,2, \ldots$, is referred to as firm $t$. Firm $i$, where $i=1,2, \ldots$, produces a level of output $\alpha Q^{i}$, where $\alpha$ is a positive parameter and it reflects the size of the firm relative to the market and where $Q^{i}$ is 
randomly taken upon entry period from the interval $[\underline{Q}, \bar{Q}], 0<\underline{Q}<\bar{Q}<+\infty$.

The demand function for firm $i, i=1,2, \ldots$, at time $t, t \geq i$, is as follows,

$$
P_{t}^{i}\left(\alpha Q^{i}\right)=A^{i}\left(1-\sum_{\substack{j \in S_{t-1} \\ j \neq i}} B^{j} \alpha Q^{j}\right)-a^{i} \alpha Q^{i}
$$

where the parameters $A^{i}, B^{j}$, and $a^{i}$ belong to the intervals $[\underline{A}, \bar{A}],[\underline{B}, \bar{B}]$, and $[\underline{a}, \bar{a}]$, $0<\underline{A}<\bar{A}<+\infty, 0<\underline{B}<\bar{B}<+\infty$, and $0<\underline{a}<\bar{a}<+\infty$, respectively. $A^{i}$ is firm $i$ 's price-intercept when all other firms are producing zero output. From hereon, $A^{i}$ will be referred to as firm $i$ 's base intercept of its demand curve. $S_{t-1}$ is a set of firms that enter before time period $t$ and are producing at time period $t$, excluding firm $t$. The above indicates that different firms' demand curves may have different slopes and different intercepts, but each firm has the same impact (i.e., $B^{j}$ is the same for $i=1,2, \ldots$ ) on the intercepts of all other firms' demand curves.

There is entry cost in the industry. Firm $i^{\prime} s$ average entry cost is assumed to be $\beta^{i} k$, where $\beta^{i} \in[\underline{\beta}, \bar{\beta}], 0<\underline{\beta}<\bar{\beta}<+\infty$, and $k>0$. Firm $i^{\prime} s$ entry cost incurs only upon entry and there are no longer entry costs for firm $i$ in all subsequent time periods after its entry.

Firm $i$ 's average cost functions is denoted as $C^{i}(\cdot), C^{i}(\cdot)$ is continuous and it has a negative first derivative and a positive second derivative, i.e., $\frac{\partial C^{i}\left(Q^{i}\right)}{\partial Q^{i}}<0, \frac{\partial^{2} C^{i}\left(Q^{i}\right)}{\partial Q^{i}}>0$. Furthermore, for given parameters $\underline{Q}^{*}$ and $\bar{Q}^{*}$, where $\underline{Q}^{*}>\underline{Q}$ and $\bar{Q}^{*}<\bar{Q}$, there exists a $Q_{i}^{*} \in\left[\underline{Q}^{*}, \bar{Q}^{*}\right]$ such that

$$
\frac{\partial C^{i}\left(Q^{i}\right)}{\partial Q^{i}} \underset{Q^{i}=Q_{i}^{*}}{\mid}=-a_{i}
$$


and

$$
C^{i}\left(Q_{i}^{*}\right)=c_{i}^{*}
$$

The parameters $A^{i}, B^{i}, a^{i}, Q^{i}, \beta^{i}$, and $c_{i}^{*}$ are firm $i$-specific and they are, in the beginning of firm $i$ 's entry period, randomly and mutually independently taken from the intervals $[\underline{A}, \bar{A}],[\underline{B}, \bar{B}],[\underline{a}, \bar{a}],[Q, \bar{Q}],[\underline{\beta}, \bar{\beta}]$, and $\left[\underline{c}^{*}, \bar{c}^{*}\right]$ according to some given distributions with full support. In addition, firm $i$ 's average cost function $C^{i}(\cdot)$ is firm- $i$ specific. It is also drawn, after the values of $a^{i}$ and $c_{i}^{*}$ are taken, in the beginning of firm $i$ 's entry period from $U^{i}$ according to a given distribution with full support, where ${ }^{2}$

$$
U^{i}=\left\{f(\cdot):[\underline{Q}, \bar{Q}] \rightarrow(\underline{c},+\infty), f(\cdot) \text { is continuous and } f^{\prime}(\cdot)<0, f^{\prime \prime}(\cdot)>0\right.
$$

$$
\text { furthermore, there exists } \left.Q_{i}^{*} \in\left[\underline{Q}^{*}, \bar{Q}^{*}\right] \text { such that } f\left(Q_{i}^{*}\right)=c_{i}^{*}, f^{\prime}\left(Q_{i}^{*}\right)=-a^{i}\right\}
$$

Since the purpose of this paper is to show the convergence of the industry to a monopolistically competitive equilibrium where the size of each firm is infinitesimally small relative to the market demand, it is necessary to transform the average cost function of each firm as a function of the scale parameter $(\alpha)$ while preserving the relevant properties of the original average cost function. This $\alpha$ - transformation is an effective way of shrinking the scale of the firm relative to the aggregate market demand. This technique has been used in papers such as Novshek (1985), Robson (1990), Luo (1995) and Luo (2007). The shrinking of the scale parameter $\alpha$ towards zero represents increased competition among firms.

\footnotetext{
${ }^{2}$ The reason for conditioning the choice of $C^{i}(\cdot)$ on the values of $a^{i}$ and $c_{i}^{*}$ is to ensure that for any given demand curve there exists $Q_{i}^{*} \in\left[Q^{*}, \bar{Q}^{*}\right]$ at which a shifted demand curve would eventually be tangent to firm $i$ 's average cost curve. Otherwise, a random picking of $C^{i}(\cdot)$ might mean no such tangency would occur for $Q^{i} \in\left[\underline{Q}^{*}, \bar{Q}^{*}\right]$. From the perspective of analyzing a monopolistically competitive equilibrium, this would be uninteresting.
} 
The $\alpha$-transformed average cost function for firm $i$ is defined as $C_{\alpha}^{i}(\cdot)$ according to

$$
C_{\alpha}^{i}\left(Q^{i}\right)=C^{i}\left(\frac{Q^{i}}{\alpha}\right)+a^{i}\left(\frac{Q^{i}}{\alpha}-Q_{i}^{*}\right)-a^{i}\left(Q^{i}-\alpha Q_{i}^{*}\right) .
$$

If $\alpha=1, C_{\alpha}^{i}(\cdot)$ is the same as $C^{i}(\cdot)$. This $\alpha$-transformed average cost function for firm $i$ generates a family of average cost functions, which shifts towards the $\mathrm{Y}$-axis as $\alpha$ shrinks towards zero and it preserves the same slope and the same magnitude of the firm $i^{\prime} s$ cost function at the output level $\alpha Q^{*}$ as $\alpha$ shrinks. Furthermore, firm $i^{\prime} s$ average cost at the output level of $\alpha Q_{i}$ is above the corresponding point on the tangent line to firm $i^{\prime} s$ average cost curve going through the point $\left(\alpha Q_{i}^{*}, c_{i}^{*}\right)$. These properties of firm $i^{\prime} s$ average cost function are formally stated in Proposition 1.

Proposition 1 (1) For any given $\alpha, C_{\alpha}^{i}\left(\alpha Q_{i}^{*}\right)=C^{i}\left(Q_{i}^{*}\right)=c_{i}^{*}$ for any $i=1,2, \ldots$

(2) For any given $\alpha, \frac{\partial C_{\alpha}^{i}\left(\alpha Q^{i}\right)}{\partial\left(\alpha Q^{i}\right)} \underset{\alpha Q^{i}=\alpha Q_{i}^{*}}{\mid}=\frac{\partial C^{i}\left(Q^{i}\right)}{\partial Q^{i}} \underset{Q^{i}=Q_{i}^{*}}{\mid}=-a^{i}$; for any $i=1,2, \ldots$

(3) $C_{\alpha}^{i}\left(\alpha Q_{i}\right) \geq c_{i}^{*}+a^{i} \alpha\left(Q_{i}^{*}-Q^{i}\right)$.

Proof. See Appendix A for the proof.

In addition, this $\alpha$-transformation ensures that firm $i^{\prime} s$ profit maximizing point $Q_{i}^{*}$ remain the same. This is formally stated in the following proposition.

Firm $i$ 's normalized per unit profit at time period $t$, where $t \geq i \geq 1$, is defined as $\Pi_{t}^{i}\left(\alpha Q^{i}\right)$ according to

$$
\Pi_{t}^{i}\left(\alpha Q^{i}\right)= \begin{cases}\frac{P_{t}^{i}\left(\alpha Q^{i}\right)-C_{\alpha}^{i}\left(\alpha Q^{i}\right)-\beta^{i} k}{A^{i}}, & \text { if } i=t \\ \frac{P_{t}^{i}\left(\alpha Q^{i}\right)-C_{\alpha}^{i}\left(\alpha Q^{i}\right)}{A^{i}}, & \text { if } i<t .\end{cases}
$$

Then, the following is true. 
Proposition 2 the normalized per unit profit for firm $i$ that produces at $\alpha Q_{i}^{*}$ is maximized, i.e.,

$$
\Pi_{t}^{i}\left(\alpha Q^{i}\right) \underset{Q^{i}=Q_{i}^{*}}{\mid} \geq \max _{Q^{i} \in[\underline{Q}, \bar{Q}]} \Pi_{t}^{i}\left(\alpha Q^{i}\right) .
$$

Proof. See Appendix A for the proof.

Luo (1995) and Luo (2007) presents their models where all firms have the conventional symmetric demand curves and the same average cost curves. Both papers show that the ultimate surviving firms are those that act as if they were profit maximizers. Obviously, in this more general setting where firms have different demand curves and different average cost curves, some firms have more technological advantage or face better market conditions. Interesting questions to be asked are whether the long run survivors are still those that happen to produce at their profit maximizing outputs; and, whether more efficient technologies and better market conditions play any role in determining the long run survivors.

The following proposition shows that each time period with a strictly positive probability (however small) firms enter with the most efficient technology and facing the best market conditions along with producing at their profit maximizing outputs.

Proposition 3 For any given $\epsilon>0$, there exists a $\theta \in[0,1]$, such that for $i=1,2, \ldots$, $\operatorname{Pr}\left(C_{\alpha}^{i}\left(\alpha Q^{i}\right) \in\left[c_{i}^{*}, c_{i}^{*}+\epsilon\right], \frac{C_{\alpha}^{i}\left(\alpha Q^{i}\right)}{A^{i}} \in\left[\frac{\underline{c}^{*}}{\overline{\bar{A}}}, \frac{c^{*}}{\overline{\bar{A}}}+\frac{\epsilon}{\bar{A}}\right]\right)=\theta>0$.

Proof. See appendix A for the proof.

Remark: Essentially, Proposition 3 says that in each time period, there is a strictly positive probability that a firm enters, producing at the tangency of its average cost curve to its demand curve, having the most efficient technology and facing the best market conditions. In fact, those firms resemble the profit maximizing firms and have 
the ratio of its profit maximizing average cost to the base intercept of its demand curve being the smallest among all firms producing at tangency points.

A firm's wealth at the end of a time period is defined as an accumulative profits up to the end of that time period. If a firm's wealth at the end of one time period is negative, then this firm must exit the industry at the end of that time period. Otherwise, this firm will continue to produce in the next time period. This assumption serves as a market selection criterion. The detail dynamics of the industry is described in the following.

For simplicity, it is assumed that there is no firm in the industry at the initial time period. At the beginning of time period 1, only one firm (called firm 1) enters the industry, producing $\alpha Q^{1}$ of product 1 . The price of product 1 at time 1 is $P_{1}^{1}\left(\alpha Q^{1}\right)=$ $A^{1}\left(1-\sum_{i \in S_{0}}\left(B^{i} \alpha Q^{i}\right)\right)-a^{1} \alpha Q^{1}$, where $S_{0}$ is a set of firms that have entered before time period 1 and are producing in time period 1 . By the assumption, $S_{0}=\phi$. Hence, the price for product 1 of firm 1 is $P_{1}^{1}\left(\alpha Q^{1}\right)=A^{1}-a^{1} \alpha Q^{1}$. Firm 1's total entry cost is $\beta^{1} k \alpha Q^{1}$ and its average cost is $C_{\alpha}\left(\alpha Q^{1}\right)$. It follows that firm 1's profit at time 1 is $\left(P_{1}^{1}\left(\alpha Q^{1}\right)-C_{\alpha}\left(\alpha Q^{1}\right)-\beta^{1} k\right) \alpha Q^{1}$. Firm 1's wealth at the end of time period 1 is defined as $W_{1}^{1}=\left(P_{1}^{1}\left(\alpha Q^{1}\right)-C_{\alpha}\left(\alpha Q^{1}\right)-\beta^{1} k\right) \alpha Q^{1}$. Firm 1 continues to produce $\alpha Q^{1}$ of product 1 at time 2 if $W_{1}^{1} \geq 0$ and otherwise exits the industry at the end of time 1.

At the beginning of time period 2, another firm (labeled as firm 2) enters the industry, producing $\alpha Q^{2}$ of product 2 . The price for product 2 at time 2 is $P_{2}^{2}\left(\alpha Q^{2}\right)=A^{2}(1-$ $\left.\sum_{i \in S_{1}}\left(B^{i} \alpha Q^{i}\right)\right)-a^{2} \alpha Q^{2}$, where $S_{1}$ is a set of firms, which entered in time period 1 and are continuing to produce at time 2. Specifically, $S_{1}=\left\{1: W_{1}^{1} \geq 0\right\} \cup \phi$. Firm 2's total entry cost is $\beta^{2} k \alpha Q^{2}$ and its average cost is $C_{\alpha}\left(\alpha Q^{2}\right)$; hence, firm 2's profit at time 2 is $\left(P_{2}^{2}\left(\alpha Q^{2}\right)-C_{\alpha}\left(\alpha Q^{2}\right)-\beta^{2} k\right) \alpha Q^{2}$. Firm 2's wealth at the end of time period 2 is defined as $W_{2}^{2}=\left(P_{2}^{2}\left(\alpha Q^{2}\right)-C_{\alpha}\left(\alpha Q^{2}\right)-\beta^{2} k\right) \alpha Q^{2}$. Firm 2 continues to produce $\alpha Q^{2}$ of product 
2 at time 3 if $W_{2}^{2} \geq 0$ and otherwise exits at the end of its entry period 2 .

If firm 1 is producing $\alpha Q^{1}$ of product 1 at time 2 (i.e., firm 1 has had a nonnegative wealth at time 1), then firm 1 has survived period 1 and continues producing $\alpha Q^{1}$ of product 1 in the industry in time period 2. Firm 1's product price at time 2 is $P_{2}^{1}\left(\alpha Q^{1}\right)=A^{1}\left(1-\sum_{i \in S_{1} \cup\{2\}, i \neq 1}\left(B^{i} \alpha Q^{i}\right)\right)-a^{1} \alpha Q^{1}$. Note that the entry firm (i.e., firm 2) is included from the intercept of firm 1's demand function at time period 2. If firm 1's wealth is nonnegative at the end of time period 1, then firm 1's wealth at the end of time period 2 is defined as an accumulative profits up to the end of time period 2. That is, $W_{2}^{1}=W_{1}^{1}+\left(P_{2}^{1}\left(\alpha Q^{1}\right)-C_{\alpha}\left(\alpha Q^{1}\right)\right) \alpha Q^{1}$. Furthermore, firm 1 continues to produce $\alpha Q^{1}$ of product 1 at time 3 if firm 1 's wealth is nonnegative at time 2 (i.e., $W_{2}^{1} \geq 0$ ) and otherwise, firm 1 exits at the end of time period 2 .

This process goes on and on. In general, at the beginning of time $t$, one firm (labeled as firm $t$ ) enters the industry, producing $\alpha Q^{t}$ of product $t$. The price of product $t$ at time $t$ is $P_{t}^{t}\left(\alpha Q^{t}\right)=A^{t}\left(1-\sum_{i \in S_{t-1}}\left(B^{i} \alpha Q^{i}\right)\right)-a^{t} \alpha Q^{t}$, where $S_{t-1}$ is a set of firms, which entered before and in time period $t-1$ and are still producing at time $t$, i.e., $S_{t-1}=\{i \leq t-1$ : $W_{i}^{i} \geq 0, W_{t^{\prime}}^{i} \geq 0$ for all $\left.t^{\prime} \in(i, t-1]\right\} \cup \phi$, where $W_{i}^{i}=\left(P_{i}^{i}\left(\alpha Q^{i}\right)-C_{\alpha}\left(\alpha Q^{i}\right)-\beta^{i} k\right) \alpha Q^{i}$ and $W_{t^{\prime}}^{i}=W_{t^{\prime}-1}^{i}+\left(P_{t^{\prime}-1}^{i}\left(\alpha Q^{i}\right)-C_{\alpha}\left(\alpha Q^{i}\right)\right) \alpha Q^{i}$ for all $t^{\prime} \in(i, t-1]$. In other words, $S_{t-1}$ is a set of firms that have survived all time periods up to the end of time period $t-1$ and remain in the market at time $t$. Firm $t^{\prime}$ s total entry cost is $\beta^{t} k \alpha Q^{t}$ and its average cost is $C_{\alpha}\left(\alpha Q^{t}\right)$; hence, firm $t^{\prime}$ 's profit at time $t$ is $\left(P_{t}^{t}\left(\alpha Q^{t}\right)-C_{\alpha}\left(\alpha Q^{t}\right)-\beta^{t} k\right) \alpha Q^{t}$. Firm $t^{\prime} s$ wealth is $W_{t}^{t}=\left(P_{t}^{t}\left(\alpha Q^{t}\right)-C_{\alpha}\left(\alpha Q^{t}\right)-\beta^{t} k\right) \alpha Q^{t}$. Firm $t$ continues to produce $\alpha Q^{t}$ of product $t$ at time $t+1$, if firm $t$ 's wealth is nonnegative and otherwise firm $t$ exits at the end of time period $t$.

If firm $i$, where $i<t$, has nonnegative wealth in all time periods before time $t$, (i.e., 
$W_{i}^{i} \geq 0, W_{t^{\prime}}^{i} \geq 0$ for all $\left.t^{\prime} \in(i, t-1]\right)$, then firm $i$ has survived all time periods up to the end of time $t-1$ and remains producing $\alpha Q^{i}$ of product $i$ in the industry in time period t. Firm $i$ 's product price at time $t$ is $P_{t}^{i}\left(\alpha Q^{i}\right)=A^{i}\left(1-\sum_{j \in S_{t-1} \cup\{t\}, j \neq i}\left(B^{j} \alpha Q^{j}\right)\right)-a^{i} \alpha Q^{i}$. Note that the entry firm (i.e., firm $t$ ) is included from the intercept of firm $i$ 's demand function at time period $t$. If firm $i$ 's wealth is nonnegative at the end of time period $t-1$, then firm $i$ 's wealth at the end of time period $t$ is defined as an accumulative profits up to the end of time period $t$. That is, $W_{t}^{i}=W_{t-1}^{i}+\left(P_{t}^{i}\left(\alpha Q^{i}\right)-C_{\alpha}\left(\alpha Q^{i}\right)\right) \alpha Q^{i}$. Furthermore, firm $i$ continues to produce $\alpha Q^{i}$ of product $i$ at time $t+1$ if firm $i^{\prime} s$ wealth is nonnegative at time $t$ (i.e., $W_{t}^{i} \geq 0$ ) and otherwise, firm $i$ exits at the end of time period $t$.

To ensure that all firms producing at arbitrarily close to their profit maximizing outputs can potentially make positive profits upon their entry periods, it is assumed that $A^{i}>c_{i}^{*}+\beta^{i} k$ for $i=1,2, \ldots$ Otherwise, no such firm can make positive profit upon its entry period and consequently no such firm can survive in the industry for more than one period.

\section{The Results}

Under the firm-specific cost curves and the firm-specific demand curves, the following theorem shows that as the size of each firm becomes infinitesimally small relative to the market, as the entry cost becomes sufficiently small, and as time gets sufficiently large, the industry converges in probability to the monopolistically competitive equilibrium, where the only surviving firms are those producing at outputs on their average cost

curves tangent to their demand curves, and furthermore at these outputs the ratios of their average costs to the base intercepts of their demand curves are the smallest among 
all firms producing at tangency outputs. Firms that have such smallest ratios are those having the most efficient technologies and facing the best market conditions. The results are precisely stated in the following theorem.

Theorem 1 For any given positive numbers $\epsilon$ and $\eta \in(0,1)$, there exist positive numbers $\bar{\alpha}$ and $\bar{k}$ such that, for any $\alpha<\bar{\alpha}$ and for $\frac{2 \bar{A} \epsilon}{\underline{\beta}(2 \underline{A}+\bar{A})}<k<\bar{k}$, there exists a time period $\tau(\epsilon, \eta, \alpha, k)$ such that, for all $t>\tau(\epsilon, \eta, \alpha, k)$,

(i(a))

$\operatorname{Pr}\left(\begin{array}{c}\underline{c}^{*} \frac{A^{i}}{\bar{A}}+a^{i} \alpha\left(Q_{i}{ }^{*}-Q^{i}\right)<P_{t}^{i}\left(\alpha Q^{i}\right)<\underline{c}^{*} \frac{A^{i}}{\bar{A}}+a^{i} \alpha\left(Q_{i}^{*}-Q^{i}\right)+\epsilon, \\ \text { for all } i \in\{t\} \cup S_{t}\end{array}\right)>1-\eta ;$

$(i(b))$

$$
\operatorname{Pr}\left(\begin{array}{c}
c_{i}^{*}+a^{i} \alpha\left(Q_{i}^{*}-Q^{i}\right)<P_{t}^{i}\left(\alpha Q^{i}\right)<c_{i}^{*}+a^{i} \alpha\left(Q_{i}^{*}-Q^{i}\right)+\epsilon, \\
\text { for } i \in\{t\} \cup S_{t} \cap\left\{i^{\prime}: \frac{c_{i^{\prime}}^{*}}{A^{i^{\prime}}} \in\left[\frac{c^{*}}{\bar{A}}, \frac{c^{*}}{\bar{A}}+\frac{\epsilon}{2 \underline{A}+\bar{A}}\right]\right\} .
\end{array}\right)>1-\eta ;
$$

(ii) with probability of at least $1-\eta$, each of the remaining firms, say firm $i$, is the one with $\frac{c_{i}^{*}}{A^{i}} \in\left[\frac{c^{*}}{\bar{A}}, \frac{c^{*}}{\bar{A}}+\frac{\epsilon}{\bar{A}}\right]$ and having the average costs lying in the interval $\left[c_{i}^{*}+a^{i} \alpha\left(Q_{i}^{*}-Q^{i}\right), c_{i}^{*}+a^{i} \alpha\left(Q_{i}^{*}-Q^{i}\right)+\epsilon\right)$, i.e.,

$\operatorname{Pr}\left(\begin{array}{c}c_{i}^{*}+a^{i} \alpha\left(Q_{i}^{*}-Q^{i}\right) \leq C_{\alpha}^{i}\left(\alpha Q^{i}\right)<c_{i}^{*}+a^{i} \alpha\left(Q_{i}^{*}-Q^{i}\right)+\epsilon \\ \text { and } \frac{c_{i}^{*}}{A^{i}} \in\left[\frac{c^{*}}{\overline{\bar{A}}}, \frac{c^{*}}{\overline{\bar{A}}}+\frac{\epsilon}{\bar{A}}\right], \text { for all } i \in S_{t}\end{array}\right)>1-\eta ;$

(iii) with probability of at least $1-\eta$, no new entrant firm, say firm $t$, with the average cost lying outside the interval $\left[c_{t}^{*}+a^{t} \alpha\left(Q_{t}^{*}-Q^{t}\right), c_{t}^{*}+a^{t} \alpha\left(Q_{t}^{*}-Q^{t}\right)+\epsilon\right)$ or satisfying $\frac{c_{t}^{*}}{A^{t}} \notin\left[\frac{\underline{c}^{*}}{\bar{A}}, \frac{c^{*}}{\bar{A}}+\frac{\epsilon}{\bar{A}}\right]$ can make positive profit by entry. That is, for firm $t$, producing $\alpha Q^{t}$, 


$$
\begin{gathered}
\text { where } C_{\alpha}^{t}\left(\alpha Q^{t}\right) \notin\left[c_{t}^{*}+a^{t} \alpha\left(Q_{t}^{*}-Q^{t}\right), c_{t}^{*}+a^{t} \alpha\left(Q_{t}^{*}-Q^{t}\right)+\epsilon\right) \text { or } \frac{c_{t}^{*}}{A^{t}} \notin\left[\frac{\underline{c}^{*}}{\bar{A}}, \frac{\underline{c}^{*}}{\bar{A}}+\frac{\epsilon}{\bar{A}}\right], \\
\operatorname{Pr}\left(P_{t}^{t}\left(\alpha Q^{t}\right)-C_{\alpha}^{t}\left(\alpha Q^{t}\right)-\beta^{t} k<0\right)>1-\eta .
\end{gathered}
$$

Proof. See Appendix B for the proof.

Remark: Shrinking the $\alpha$ and $k$ represents ways of shrinking the scale of firms relative to the market and shrinking entry costs to zero, respectively. As the $\alpha$ and $k$ get smaller, the industry eventually comes closer to monopolistic competition as time goes by. In the limit, monopolistic competition evolves as a long run outcome of the industry where firms are producing at the tangency of their average cost curves to their respective demand curves, where firms are infinitesimally small relative to the market and where there is no entry barrier. The technical characterizations of the long run equilibrium outcomes are provided in Theorem 1. According to Part (ib), prices of all producing firms are arbitrarily close to $c_{i}^{*}$ where their average cost curves is tangent to their respective demand curves. Notice from part (ia)that the prices for some firms could be below their average costs (due to $\underline{c}^{*} \frac{A^{i}}{\bar{A}}<c_{i}^{*}$ ). Nevertheless, part (ii) indicates that such firms would not survive in the long run. According to part (ii), the only surviving firms are those producing at arbitrarily close to the tangency of their average cost curves to their respective demand curves (i.e., resembling profit maximizing firms), and using a technology arbitrarily close to the most efficient technology (with $\underline{c}^{*}$ ) and serving a market arbitrarily close to the largest market (with $\bar{A}$ ) (i.e., facing the best market conditions). Furthermore, part (iii) indicates that no new entrant firms not producing at arbitrarily close to the tangency output or not having the most efficient technology or not facing the best market conditions, could enter and make positive profits. In addition, it is worth mentioning that in the process of shrinking the $\alpha$ and $k$, the $k$ 
must be maintained to be sufficiently high relative to the scale of parameter $\alpha$. This is

reflected in the lower bound, $\frac{2 \bar{A} \epsilon}{\underline{\beta}(2 \underline{A}+\bar{A})}$, for the $k$. Otherwise, the entry cost loses its role of creating entry barriers to the industry.

Furthermore, the results in Theorem 1 suggest that the long run survivors are producing at a suboptimal scale of their outputs in the sense that their output levels are less than their minimum efficient scales. This is consistent with the well documented empirical findings in the industrial organization literature (see Weiss (1963 and 1976), Scherer (1973), and Pratten (1971)) that a majority of firms are not only small but also sufficiently small so as to operate at a suboptimal scale of output (instead of the minimum efficient scale) in most industries.

\section{Conclusion}

This paper builds a dynamic model of an industry where firms produce similar but differentiated products. Firms have different entry costs and average cost functions as well. Firms face different demand functions.

Conventionally, to achieve monopolistic competition, the key driving force is that firms are assumed to maximize profits in their entry decision, in selecting output level and in their decision of when to exit the industry (see Chamberlin (1933) and Robinson (1933)). However, due to the recent criticism on firms' rationality, this paper attempts to explain monopolistic competition without purposive profit maximization assumption. This is achieved by applying an evolutionary idea of natural selection to the industry competition. Firms enter the industry regardless of the existence of profits; firms' outputs are randomly determined rather than generated from profit maximization problems; and firms exit the industry if their wealth is negative. 
A group of papers in this literature provide positive support to the hypothesis of the "as if" profit maximizers as long run survivors through market selection argument. This paper shows that not all of these firms will survive in this general setting of industry. The only long run survivors are those that possess the most efficient technology, face the most favorable market conditions and produce at their profit maximizing outputs. Moreover, at the aggregate level, monopolistic competition arises in the long run. This paper modifies and supports the classic argument for the derivation of monopolistic competition. In addition, the results in this paper is consistent with the common observation in the industrial organization that a majority of the firms are not only small but also sufficiently small so as to operate at suboptimal scale of output (instead of the minimum efficient scale) in most industries. 


\section{Appendix A}

Proof of Proposition 1: (1) The result can be obtained by replacing $Q^{i}$ with $\alpha Q_{i}^{*}$ in equation (4) and then applying equation (3) to the resulting equation.

(2) Rewrite equation (4) into the following:

$$
C_{\alpha}^{i}\left(\alpha Q^{i}\right)=C^{i}\left(Q^{i}\right)+a^{i}\left(Q^{i}-Q_{i}^{*}\right)-a^{i}\left(\alpha Q^{i}-\alpha Q_{i}^{*}\right)
$$

then taking a derivative of the above equation and then applying equation (2) results in the following equation:

$$
\frac{\partial C_{\alpha}^{i}\left(\alpha Q^{i}\right)}{\partial\left(\alpha Q^{i}\right)} \underset{\alpha Q^{i}=\alpha Q_{i}^{*}}{\mid}=\frac{\partial C^{i}\left(Q^{i}\right)}{\partial Q^{i}} \underset{Q^{i}=Q_{i}^{*}}{\mid}=-a^{i} .
$$

(3) Since $C_{\alpha}^{i}\left(\alpha Q_{i}^{*}\right)=c_{i}^{*}$ for any $i=1,2, \ldots, \frac{\partial C_{\alpha}^{i}\left(\alpha Q^{i}\right)}{\partial\left(\alpha Q^{i}\right)} \underset{\alpha Q^{i}=\alpha Q_{i}^{*}}{\mid}=-a^{i}$; and $\frac{\partial^{2} C_{\alpha}^{i}\left(\alpha Q^{i}\right)}{\partial\left(\alpha Q^{i}\right)^{2}}>$ 0 , the result follows.

Proof of Proposition 2: Substitute equations (1) and (4) into equation (5). Then use the resulting equation and take the first order and the second order of firm $i^{\prime}$ s normalized per unit of profit with respect to $Q^{i}$. Finally apply property (2) of Proposition 2 along with the assumption of $\frac{\partial^{2} C_{\alpha}^{i}\left(\alpha Q^{i}\right)}{\partial\left(\alpha Q^{i}\right)^{2}}>0$ to obtain equation (6).

Proof of Proposition 3: Since, conditional on $a^{i}$ and $c_{i}^{*}$, the random draws of $Q^{i}$ and the continuous average cost function $C^{i}(\cdot)$ are mutually independent, it follows that $C^{i}\left(\alpha Q^{i}\right)$ has a strictly positive probability of taking a value in the interval $\left[c_{i}^{*}, c_{i}^{*}+\epsilon\right]$, where $\epsilon$ is any given small positive number. It is also true that $C^{i}\left(\alpha Q^{i}\right)$ has a strictly positive support at $\underline{c}^{*}$. Finally, since $A^{i}$ has a strictly positive support at $\bar{A}$, and given the fact that $A^{i}$ is independent of all the random variables $a^{i}, c_{i}^{*}, Q^{i}$, and $C^{i}(\cdot)$ and given 
the $\alpha$-transformation of the average cost function, it follows that with a strictly positive probability,

$$
\operatorname{Pr}\left(C_{\alpha}^{i}\left(\alpha Q^{i}\right) \in\left[c_{i}^{*}, c_{i}^{*}+\epsilon\right], \frac{C_{\alpha}^{i}\left(\alpha Q^{i}\right)}{A^{i}} \in\left[\frac{\underline{c}^{*}}{\bar{A}}, \frac{c^{*}}{\bar{A}}+\frac{\epsilon}{\bar{A}}\right]\right)>0
$$

Furthermore, given that the sequences $\left\{a^{i}\right\}_{i \geq 1},\left\{c_{i}^{*}\right\}_{i \geq 1},\left\{Q^{i}\right\}_{i \geq 1}$ and $\left\{C^{i}(\cdot)\right\}_{i \geq 1}$ are independently and identically distributed, respectively; since $Q^{i}$ is independent of $a^{j}, c_{j}^{*}$ and $C^{j}(\cdot)$ for $i, j=1,2, \ldots$; the $a^{i}$ is independent of $c_{j}^{*}$ for all $i$ and $j$; and the $C^{i}(\cdot)$ is independent of $a^{j}$ and $c_{j}^{*}$ for $i \neq j$, it follows that there must exists a $\theta \in(0,1)$, such that for $i=1,2, \ldots, \operatorname{Pr}\left(C_{\alpha}^{i}\left(\alpha Q^{i}\right) \in\left[c_{i}^{*}, c_{i}^{*}+\epsilon\right], \frac{C_{\alpha}^{i}\left(\alpha Q^{i}\right)}{A^{i}} \in\left[\frac{c^{*}}{\bar{A}}, \frac{c^{*}}{\bar{A}}+\frac{\epsilon}{\bar{A}}\right]\right)=\theta$

\section{Appendix B}

Theorem 1 is directly established by using the results in two lemmas, namely, Lemma 1 and Lemma 2. Lemmas 1 and 2 are first proven.

For the purpose of simplifying the proof, denote $q^{i}=a^{i} Q^{i}$ for any $i, q_{i}^{*}=a^{i} Q_{i}^{*}$ for any $i$, and $b^{j}=\frac{B^{j}}{a^{j}}$ for any $j$ and furthermore, define $\underline{q}=\underline{a} \underline{Q}, \bar{q}=\bar{a} \bar{Q}, \underline{q}^{*}=\underline{a} \underline{Q}^{*}, \bar{q}^{*}=\bar{a} \bar{Q}^{*}$, $\underline{b}=\frac{B}{\bar{a}}$ and $\bar{b}=\frac{\bar{B}}{\underline{a}}$. Therefore, firm $i^{\prime} s$ demand function can be expressed, in terms of $q^{i}$, as follows:

$$
P_{t}^{i}\left(\alpha Q^{i}\right)=P_{t}^{i}\left(\alpha \frac{q^{i}}{a^{i}}\right)=A^{i}\left(1-\sum_{\substack{j \in S_{t-1} \\ j \neq i}} b^{j} \alpha q^{j}\right)-\alpha q^{i}
$$

where $q^{i} \in[\underline{q}, \bar{q}]$ and $b^{j} \in[\underline{b}, \bar{b}]$. Similarly, firm $i^{\prime} s$ average cost function can also be expressed, in terms of $q^{i}$, as

$$
C_{\alpha}^{i}\left(\alpha Q^{i}\right)=C_{\alpha}^{i}\left(\frac{\alpha q^{i}}{a^{i}}\right)=C^{i}\left(\frac{q^{i}}{a^{i}}\right)+\left(q^{i}-q_{i}^{*}\right)-\alpha\left(q^{i}-q_{i}^{*}\right)
$$


Define $p_{t}^{i}\left(\alpha q^{i}\right)=P_{t}^{i}\left(\alpha \frac{q^{i}}{a^{i}}\right)$ and define $c_{\alpha}^{i}\left(\alpha q^{i}\right)=C_{\alpha}^{i}\left(\frac{\alpha q^{i}}{a^{i}}\right)$. Notice that for the above transformation, $c_{\alpha}^{i}\left(\alpha q^{i}\right)=C_{\alpha}^{i}\left(\alpha Q^{i}\right)$; therefore, $c_{\alpha}^{i}\left(\alpha q_{i}^{*}\right)=C_{\alpha}^{i}\left(\alpha Q_{i}^{*}\right)=C^{i}\left(Q_{i}^{*}\right)=c_{i}^{*}$. $p_{t}^{i}\left(\alpha q^{i}\right)=P_{t}^{i}\left(\alpha Q^{i}\right)$. In addition, for any given $\alpha,\left.\frac{\partial c_{\alpha}^{i}\left(\alpha q^{i}\right)}{\partial\left(\alpha q^{i}\right)}\right|_{\alpha q^{i}=\alpha q_{i}^{*}}=\frac{\partial p_{t}^{i}\left(\alpha q^{i}\right)}{\partial\left(\alpha q^{i}\right)}=-1$, for any $i=1,2, \ldots$ This means that the slope of a firm's tangent line to its average cost function at the output level of $\alpha q_{i}^{*}$ is the same across all firms.

Furthermore, normalize the following variables by $A^{i}$. That is, define, for $i=1,2, \ldots$, $\widetilde{p}_{t}^{i}\left(\alpha q^{i}\right)=\frac{p_{t}^{i}\left(\alpha q^{i}\right)}{A^{i}}, \widetilde{c}_{\alpha}^{i}\left(\alpha q^{i}\right)=\frac{c_{\alpha}^{i}\left(\alpha q^{i}\right)}{A^{i}}, \widetilde{q}^{i}=\frac{q^{i}}{A^{i}}, \widetilde{q}_{i}^{*}=\frac{q_{i}^{*}}{A^{i}}, \widetilde{c}_{i}^{*}=\frac{c_{i}^{*}}{A^{i}}, \widetilde{\beta}^{i}=\frac{\beta^{i}}{A^{i}}$. Denote $\underline{\widetilde{c}}^{*}=\frac{\underline{c}^{*}}{\bar{A}}, \underline{q}^{*}=\frac{\underline{q}^{*}}{\bar{A}}, \widetilde{\bar{q}}^{*}=\frac{\bar{q}^{*}}{\underline{A}}, \underline{\widetilde{\beta}}=\frac{\bar{\beta}}{\bar{A}}$ and $\stackrel{\widetilde{\beta}}{\bar{\beta}}=\frac{\bar{\beta}}{\underline{A}}$. Hence, each firm's demand function in terms of $\widetilde{p}_{t}^{i}\left(\alpha q^{i}\right)$ has the same base intercept.

For $t=1,2, \ldots$, define $I_{t}^{t}$ as the following:

$$
I_{t}^{t}= \begin{cases}1 & \text { if } p_{t}^{t}\left(\alpha q^{t}\right) \geq c_{\alpha}^{t}\left(\alpha q^{t}\right)+\beta^{t} k \\ 0 & \text { otherwise }\end{cases}
$$

If $I_{t}^{t}=1$, then firm $t$ makes a nonnegative profit on the entry period.

Lemma 1 establishes a lower bound for firms' prices after shrinking firms' size relative to the market (i.e., $\alpha$ ). The lower bounds are arbitrarily close to $\underline{c}^{*}$ ( which is the tangency of the most efficient firms' average cost curves to their respective demand curves).

Denote $\bar{S}_{t}=\{t\} \cup S_{t-1}$ for $t=1,2, \ldots$

Lemma 1 For any given $k$, for any given positive $\epsilon^{\prime}<\frac{A \widetilde{A} k}{2}$, there exists an $\bar{\alpha}$ such that, for $\alpha<\bar{\alpha}$, at any time period $t$, where $t=1,2, \ldots$, for $i \in \bar{S}_{t}$,

$$
\widetilde{p}_{t}^{i}\left(\alpha q^{i}\right)>\underline{\widetilde{c}}^{*}+\alpha\left(\widetilde{q}_{i}^{*}-\widetilde{q}^{i}\right)+\frac{\epsilon^{\prime}}{\underline{A}} .
$$


Proof. Define

$$
\widetilde{\widehat{P}}_{t}=\left(1-\sum_{i \in S_{t}} b^{i}\left(\alpha q^{i}\right)\right), \text { for } t=1,2, \ldots
$$

Lemma 1 first proves the following claim.

Claim: For any given $k$, and for any given positive $\epsilon^{\prime}<\frac{A \underline{A} k}{2}$, there exists an $\alpha_{1}$ such that for $\alpha<\alpha_{1}, \widetilde{\widehat{P}}_{t} \geq \underline{\widetilde{c}}^{*}+\alpha \underline{\widetilde{q}}^{*}+\underline{\widetilde{\beta}} k-\frac{\epsilon^{\prime}}{\underline{A}}$, for all $t=1,2, \ldots$

Proof of Claim: This is shown by induction.

(1) The base step of the induction proof: The claim is true for $t=1$. For any given $k$, and for any given positive $\epsilon^{\prime}<\frac{\bar{A} \widetilde{\beta} k}{2}$, define $\alpha_{1}$ such that

$$
-\bar{b} \alpha_{1} \bar{q}=\alpha_{1}{\underline{q^{*}}}^{*}-\frac{\epsilon^{\prime}}{\underline{A}}, \text { or } \alpha_{1}=\frac{\epsilon^{\prime}}{\underline{A}\left(\bar{b} \bar{q}+\underline{\widetilde{q}}^{*}\right)} .
$$

Since $\widetilde{P}_{1}=\left(1-b^{1} \alpha q^{1} I_{1}^{1}\right)$. This together with equation (8) and $q^{1} \leq \bar{q}$ and $A^{1}>c_{1}^{*}+\beta^{1} k$ implies that $\widetilde{\widehat{P}}_{1} \geq 1-\bar{b} \alpha \bar{q}>\widetilde{c}_{1}^{*}+\alpha \underline{q}^{*}+\widetilde{\beta}^{1} k-\frac{\epsilon^{\prime}}{\underline{A}}>\underline{\widetilde{c}}^{*}+\alpha \underline{q}^{*}+\underline{\widetilde{\beta}} k-\frac{\epsilon^{\prime}}{\underline{A}}$, for $\alpha<\alpha_{1}$.

(2) The induction step: Suppose that the claim is true for $t=r$, i.e., for any given $k$, and for any given positive $\epsilon^{\prime}<\frac{A \widetilde{\beta} k}{2}$, there exists an $\alpha_{1}$ such that for $\alpha<\alpha_{1}$, at time period $r$,

$$
\widetilde{\widehat{P}}_{r} \geq \underline{\widetilde{c}}^{*}+\alpha \underline{\widetilde{q}}^{*}+\underline{\widetilde{\beta}} k-\frac{\epsilon^{\prime}}{\underline{A}}
$$

It is now shown that the claim is true for $t=r+1$, i.e., for the given $k$, for the given $\epsilon^{\prime}<\frac{\underline{A} \bar{\beta} k}{2}$, if $\alpha<\alpha_{1}$, then at time period $r+1$,

$$
\widetilde{\widehat{P}}_{r+1} \geq \underline{\widetilde{c}}^{*}+\alpha \underline{\widetilde{q}}^{*}+\underline{\widetilde{\beta}} k-\frac{\epsilon^{\prime}}{\underline{A}}
$$


Using equation (7),

$$
\widetilde{\widehat{P}}_{r+1}=\widetilde{\widehat{P}}_{r}-b^{r+1} \alpha q^{r+1} I_{r+1}^{r+1}+\sum_{\substack{i \in X_{r+1} \\ i \neq r+1}} b^{i}\left(\alpha q^{i}\right),
$$

where $X_{r+1}$ represents a set of firms that exit the industry at the end of time period $r+1$. Equation (11) further implies that

$$
\widetilde{\widehat{P}}_{r+1} \geq \widetilde{\widehat{P}}_{r}-b^{r+1} \alpha q^{r+1} I_{r+1}^{r+1}
$$

Consider the following two cases:

Case 1: Suppose that $\widetilde{\widehat{P}}_{r}-b^{r+1} \alpha q^{r+1} I_{r+1}^{r+1}-\alpha \widetilde{q}^{r+1} \geq \widetilde{c}_{r+1}^{*}+\alpha\left(\widetilde{q}_{r+1}^{*}-\widetilde{q}^{r+1}\right)+\underline{\widetilde{\beta}} k-\frac{\epsilon^{\prime}}{\underline{A}}$. Then, using the fact that $\widetilde{c}_{r+1}^{*} \geq \underline{\widetilde{c}}^{*}$, and $\widetilde{q}_{r+1}^{*} \geq \underline{\widetilde{q}}^{*}$, equation (12) implies that

$$
\widetilde{\widehat{P}}_{r+1} \geq \underline{\widetilde{c}}^{*}+\alpha \underline{\widetilde{q}}^{*}+\underline{\widetilde{\beta}} k-\frac{\epsilon^{\prime}}{\underline{A}} .
$$

That is, equation (10) holds.

Case 2: Suppose that

$$
\widetilde{\widehat{P}}_{r}-b^{r+1} \alpha q^{r+1} I_{r+1}^{r+1}-\alpha \widetilde{q}^{r+1}<\widetilde{c}_{r+1}^{*}+\alpha\left(\widetilde{q}_{r+1}^{*}-\widetilde{q}^{r+1}\right)+\underline{\widetilde{\beta}} k-\frac{\epsilon^{\prime}}{\underline{A}} .
$$

Notice that

$$
\frac{p_{r+1}^{r+1}\left(\alpha q^{r+1}\right)}{A^{r+1}}=\widetilde{p}_{r+1}^{r+1}\left(\alpha q^{r+1}\right)=\left(1-\sum_{i \in S_{r}} b^{i}\left(\alpha q^{i}\right)\right)-\alpha \widetilde{q}^{r+1} .
$$


Using the definition of $\widetilde{P}_{r}$ (see equation (7)),

$$
\widetilde{\widehat{P}}_{r}-b^{r+1} \alpha q^{r+1} I_{r+1}^{r+1}-\alpha \widetilde{q}^{r+1}=\left(1-\sum_{i \in S_{r}} b^{i}\left(\alpha q^{i}\right)\right)-b^{r+1} \alpha q^{r+1} I_{r+1}^{r+1}-\alpha \widetilde{q}^{r+1}
$$

Equations (14) and (15) imply that

$$
\frac{p_{r+1}^{r+1}\left(\alpha q^{r+1}\right)}{A^{r+1}}-\left(\widetilde{\widehat{P}}_{r}-b^{r+1} \alpha q^{r+1} I_{r+1}^{r+1}-\alpha \widetilde{q}^{r+1}\right)=b^{r+1} \alpha q^{r+1} I_{r+1}^{r+1}<\bar{b} \alpha \bar{q}
$$

Since, using the definition of $\alpha_{1}$ in equation (8), $\bar{b} \alpha_{1} \bar{q}=\frac{\bar{b} \bar{q}}{\underline{\widetilde{q}}^{*}+\bar{b} \bar{q}}\left(\frac{\epsilon^{\prime}}{\underline{A}}\right)<\frac{\epsilon^{\prime}}{\underline{A}}$, it follows that for any $\alpha<\alpha_{1}$,

$$
\bar{b} \alpha \bar{q}<\frac{\epsilon^{\prime}}{\underline{A}} .
$$

This together with equation (16) further implies that for $\alpha<\alpha_{1}$,

$$
\frac{p_{r+1}^{r+1}\left(\alpha q^{r+1}\right)}{A^{r+1}}<\widetilde{P}_{r}-b^{r+1} \alpha q^{r+1} I_{r+1}^{r+1}-\alpha \widetilde{q}^{r+1}+\frac{\epsilon^{\prime}}{\underline{A}}
$$

Using equations (13) and (17), it follows that for $\alpha<\alpha_{1}$,

$$
\frac{p_{r+1}^{r+1}\left(\alpha q^{r+1}\right)}{A^{r+1}}<\widetilde{c}_{r+1}^{*}+\alpha\left(\widetilde{q}_{r+1}^{*}-\widetilde{q}^{r+1}\right)+\underline{\widetilde{\beta}} k .
$$

Since properties (3) of the $\alpha$-transformed cost function outlined in Proposition 1 in Appendix A imply that any price for producing $\alpha Q^{r+1}$ on the demand curve which is tangent to the average cost curve at $\alpha Q_{r+1}^{*}$ is no higher than $C_{\alpha}^{r+1}\left(\alpha Q^{r+1}\right)$, equation 
(18), together with $A^{r+1} \underline{\widetilde{\beta}} \leq \beta^{r+1}$, implies that

$$
\begin{aligned}
p_{r+1}^{r+1}\left(\alpha q^{r+1}\right) & <c_{r+1}^{*}+\alpha\left(q_{r+1}^{*}-q^{r+1}\right)+\beta^{r+1} k \\
& \leq c_{\alpha}^{r+1}\left(\alpha q^{r+1}\right)+\beta^{r+1} k .
\end{aligned}
$$

Equation (19) further implies that firm $r+1$ makes a negative profit in its entry period. Therefore, firm $r+1$ must exit the industry at the end of its entry period $r+1$. That is,

$$
I_{r+1}^{r+1}=0 .
$$

Using equation (12), this in turn implies that

$$
\widetilde{\widehat{P}}_{r+1} \geq \widetilde{\widehat{P}}_{r}
$$

which together with equation (9) further implies that for any $\alpha<\alpha_{1}$,

$$
\widetilde{\widehat{P}}_{r+1} \geq \underline{\widetilde{c}}^{*}+\alpha \underline{\widetilde{q}}^{*}+\underline{\widetilde{\beta}} k-\frac{\epsilon^{\prime}}{\underline{A}}
$$

Therefore, the claim holds.

Now, at time period $t=1,2, \ldots$, for any firm $i \in \bar{S}_{t}=\{t\} \cup S_{t-1}$,

$$
\frac{p_{t}^{i}\left(\alpha q^{i}\right)}{A^{i}}=\widetilde{\widehat{P}}_{t-1}-\alpha\left(\widetilde{q}^{i}-b^{i} q^{i}\right)-b^{t} \alpha q^{t}
$$


This together with the result of the claim and with $q^{t} \leq \bar{q}$ implies that for any $\alpha<\alpha_{1}$,

$$
\begin{aligned}
\frac{p_{t}^{i}\left(\alpha q^{i}\right)}{A^{i}} & \geq \widetilde{c}^{*}+\alpha \underline{q}^{*}+\underline{\widetilde{\beta}} k-\frac{\epsilon^{\prime}}{\underline{A}}-\alpha\left(\widetilde{q}^{i}-b^{i} q^{i}\right)-b^{t} \alpha q^{t} \\
& =\widetilde{\widetilde{c}}^{*}+\alpha\left(\widetilde{q}_{i}^{*}-\widetilde{q}^{i}\right)+\alpha\left(\underline{\widetilde{q}}^{*}-\widetilde{q}_{i}^{*}\right)+\underline{\widetilde{\beta}} k-\frac{\epsilon^{\prime}}{\underline{A}}+\alpha b^{i} q^{i}-b^{t} \alpha q^{t} \\
& >\widetilde{\widetilde{c}}^{*}+\alpha\left(\widetilde{q}_{i}^{*}-\widetilde{q}^{i}\right)+\underline{\widetilde{\beta}} k-\frac{\epsilon^{\prime}}{\underline{A}}-\bar{b} \alpha \bar{q}-\alpha \widetilde{\bar{q}}^{*} .
\end{aligned}
$$

Then, with $\epsilon^{\prime}<\frac{\underline{A} \underline{\underline{\beta}} k}{2}$, there exists an $\bar{\alpha}<\alpha_{1}$ such that for $\alpha<\bar{\alpha}$,

$$
\underline{\widetilde{\beta}} k-\frac{\epsilon^{\prime}}{\underline{A}}-\left(\bar{b} \alpha \bar{q}+\alpha \widetilde{\bar{q}}^{*}\right)>\frac{\epsilon^{\prime}}{\underline{A}} .
$$

Therefore, the result of Lemma 1 follows from equation (20) and (21)

Lemma 2 establishes a probabilistic upper bound for firms' prices after a certain time period for a sufficiently small $\alpha$. The upper bounds are arbitrarily close to the average cost plus average entry cost of the firms producing at the tangency of their average cost curves to their respective demand curves, possessing the most efficient technology, and facing the best market conditions. The driving force of this result is the allowance for the entry of firms producing at the tangency of their average cost curves to their respective demand curves, with the most efficient technology (i.e., $\left.\underline{c}^{*}\right)$ and facing the best market conditions (i.e., $\bar{A}$ ). In other words, it is indirectly assumed that each time period with a positive probability (however small) firms enter the industry with the most efficient technology (i.e., $\left.\underline{c}^{*}\right)$ and facing the best market conditions (i.e., $\bar{A}$ ). These firms are referred to as M-firms in the proof of Lemma 2. The proof of Lemma 2 is done by way of contradiction. It roughly says that the prices cannot be above the upper bounds after a certain time period for a sufficiently small $\alpha$. If they do, then there will be a sufficiently large number of M-firms entering the industry over the time periods where the prices 
are above the upper bounds. Since these M-firms make positive profits in their entry periods and in all subsequent time periods, they never exits the industry. Over time, the presence of the sufficiently large number of M-firms in the industry will drive all prices below their lower bounds defined in Lemma 1. This is a contradiction.

Denote $q=\left(q^{1}, q^{2}, \ldots\right)$ and $Q=\left(Q^{1}, Q^{2}, \ldots\right)$.

Lemma 2 With probability 1, the following occurs: for any given $k$, and for any given positive $\epsilon^{\prime}<\frac{\bar{A} \widetilde{\beta} k}{2}$, there exists an $\bar{\alpha}$, such that, for any $\alpha<\bar{\alpha}$, there exists a time period $\tau\left(\epsilon^{\prime}, q, k, \alpha\right)$ such that, for $t>\tau\left(\epsilon^{\prime}, q, k, \alpha\right)$, for all $i \in \bar{S}_{t}=\{t\} \cup S_{t-1}$,

$$
\widetilde{p}_{t}^{i}\left(\alpha q^{i}\right)<\underline{\widetilde{c}}^{*}+\alpha\left(\widetilde{q}_{i}^{*}-\widetilde{q}^{i}\right)+\widetilde{\bar{\beta}} k+\frac{\epsilon^{\prime}}{\bar{A}}+\frac{\epsilon^{\prime}}{\underline{A}}
$$

Proof. Define $M_{t}$, for $t=1,2, \ldots$, as

$$
M_{t}=\left\{\begin{array}{l}
1 \text { if } c_{\alpha}^{t}\left(\alpha q^{t}\right) \in\left[c_{t}^{*}, c_{t}^{*}+\epsilon^{\prime}\right] \text { and } \widetilde{c}_{\alpha}^{t}\left(\alpha q^{t}\right) \in\left[\widetilde{\widetilde{c}}^{*}, \widetilde{\widetilde{c}}^{*}+\frac{\epsilon^{\prime}}{\bar{A}}\right] \\
0 \text { otherwise }
\end{array}\right.
$$

where $\epsilon^{\prime}$ is defined in Lemma 1. Using the result in Proposition 3, it follows that

$$
\operatorname{Pr}\left(M_{t}=1\right)=\theta \text { and } \operatorname{Pr}\left(M_{t}=0\right)=1-\theta \text { for } t=1,2, \ldots
$$

The firm with $M_{t}=1$ is referred to as a $M$-firm. If $M_{t}=1$, denote $q^{M}=q^{t}$ and $\widetilde{q}^{M}=\widetilde{q}^{t}$. Hence $\widetilde{q}^{M} \leq \underline{\widetilde{q}}^{*}$.

The proof begins by proving the following claim and the result in Lemma 2 follows directly from this claim.

Claim: With probability 1 , there is only a finite number of time periods, in which $\widetilde{\widehat{P}}_{t}$ 
is above $\underline{\widetilde{c}}^{*}+\alpha \underline{\widetilde{q}}^{*}+\widetilde{\bar{\beta}} k+\frac{\epsilon^{\prime}}{\bar{A}}$. That is,

$$
\operatorname{Pr}\left(\sum_{t=2}^{\infty} h_{t}<\infty\right)=1
$$

where for any $t>1$, the random variable $h_{t}$ is defined to be 1 if at time $t-1, \widetilde{\widehat{P}}_{t-1}$ is above $\widetilde{c}^{*}+\alpha \underline{q}^{*}+\widetilde{\bar{\beta}} k+\frac{\epsilon^{\prime}}{\bar{A}}$ for $\alpha<\bar{\alpha}$ and $h_{t}$ is defined to be 0 otherwise. (where $\bar{\alpha}$ is defined in Lemma 1.)

Proof of Claim: The proof is done by way of contradiction. Suppose that the claim is not true, then for some $\delta>0, \operatorname{Pr}\left(\sum_{t=2}^{\infty} h_{t}=\infty\right)>\delta$. This implies that for any given integer $J>0$, there exists a positive integer $m^{\prime} \geq J$ such that for $m>m^{\prime}$, and, for $N(m)=\sum_{t=2}^{m} h_{t}$,

$$
\operatorname{Pr}(N(m) \geq J)>\frac{\delta}{2}
$$

Now, construct a collection of random variables $\left\{\widetilde{M}_{t_{1}}, \widetilde{M}_{t_{2}}, \ldots, \widetilde{M}_{t_{N(m)}}\right\}$, where, for $i=$ $1,2, \ldots, N(m), t_{i}=\min _{t}\left\{t: h_{t}=1, t>t_{i-1}, t_{0}=0\right\}$ according to

$$
\widetilde{M}_{t_{i}}=\left\{\begin{array}{cc}
1 & \text { if } M_{t_{i}}=1 \\
0 & \text { otherwise }
\end{array}\right.
$$

Since for $i=1,2, \ldots, N(m), M_{t_{i}}$ is independent of $h_{t_{i}}$ (which is realized at $t_{i}-1$ ) and since $\left\{M_{t}\right\}_{t \geq 1}$ is independently and identically distributed, it follows that $\left\{\widetilde{M}_{t_{i}}\right\}_{i \geq 1}^{N(m)}$ is independently and identically distributed and furthermore, in each time period, $M_{t}$ and $\widetilde{M}_{t}$ have the same distribution function. This together with equation (22) implies that,

$$
\operatorname{Pr}\left(\widetilde{M}_{t_{i}}=1\right)=\theta \text { and } \operatorname{Pr}\left(\widetilde{M}_{t_{i}}=0\right)=1-\theta \text { for } i=1,2, \ldots, N(m)
$$


Since $E\left(\widetilde{M}_{t_{i}}\right)=\theta, \operatorname{Var}\left(\widetilde{M}_{t_{i}}\right)=\theta(1-\theta)$ and since $\theta \in(0,1)$, it follows that

$$
\operatorname{Var}\left(\sum_{i=1}^{N(m)} \widetilde{M}_{t_{i}}\right)<E\left(\sum_{i=1}^{N(m)} \widetilde{M}_{t_{i}}\right)
$$

Denote $Z_{N(m)}=E\left(\sum_{i=1}^{N(m)} \widetilde{M}_{t_{i}}\right)$. Using Chebyshev's inequality, for any given positive integer $x<Z_{N(m)}$,

$$
\begin{aligned}
\operatorname{Pr}\left(\sum_{i=1}^{N(m)} \widetilde{M}_{t_{i}} \leq x\right) & \leq \operatorname{Pr}\left(\left|\sum_{i=1}^{N(m)} \widetilde{M}_{t_{i}}-Z_{N(m)}\right| \geq Z_{N(m)}-x\right) \\
& \leq \frac{\operatorname{Var}\left(\sum_{i=1}^{N(m)} \widetilde{M}_{t_{i}}\right)}{\left(Z_{N(m)}-x\right)^{2}} \\
& \left.<\frac{Z_{N(m)}}{\left(Z_{N(m)}-x\right)^{2}} \text { (using equation }(25)\right)
\end{aligned}
$$

This together with the fact that $\operatorname{Pr}\left(\sum_{i=1}^{N(m)} \widetilde{M}_{t_{i}} \leq x\right)=1-\operatorname{Pr}\left(\sum_{i=1}^{N(m)} \widetilde{M}_{t_{i}}>x\right)$ implies that

$$
\operatorname{Pr}\left(\sum_{i=1}^{N(m)} \widetilde{M}_{t_{i}}>x\right)>1-\frac{Z_{N(m)}}{\left(Z_{N(m)}-x\right)^{2}}
$$

Notice that as $N(m) \rightarrow \infty, Z_{N(m)} \rightarrow \infty$ and $\frac{Z_{N(m)}}{\left(Z_{N(m)}-x\right)^{2}} \rightarrow 0$. Hence, for any given positive integer $x$ and for any given positive $y<1$, there exists a positive integer $\bar{N}$, such that for $N(m) \geq \bar{N}$,

$$
\operatorname{Pr}\left(\sum_{i=1}^{N(m)} \widetilde{M}_{t_{i}}>x\right)>1-y>0
$$

Define $\bar{m}$, such that $N(\bar{m})=\bar{N}$. Since $\sum_{i=1}^{N(m)} M_{t_{i}}=\sum_{i=1}^{N(m)} \widetilde{M}_{t_{i}}$, using equation $(26)$, it 
follows that for $m>\bar{m}$,

$$
\operatorname{Pr}\left(\sum_{i=1}^{N(m)} M_{t_{i}}>x \mid N(m)=r\right)>1-y, \text { for } r \geq \bar{N}
$$

Using Proposition 4 in Appendix C, equation (27) also implies that

$$
\operatorname{Pr}\left(\sum_{i=1}^{N(m)} M_{t_{i}}>x \mid N(m) \geq \bar{N}\right)>1-y>0 .
$$

Set $J=\bar{N}$ in equation (24). Equation (24) means that for this given $\bar{N}$, there exists a positive $m^{\prime} \geq \bar{N}$, such that for $m>m^{\prime}$,

$$
\operatorname{Pr}(N(m) \geq \bar{N})>\frac{\delta}{2}
$$

Since for $m>\max \left(m^{\prime}, \bar{m}\right)$,

$$
\begin{aligned}
\operatorname{Pr}\left(\sum_{i=1}^{N(m)} M_{t_{i}}>x\right) & \geq \operatorname{Pr}\left(\sum_{i=1}^{N(m)} M_{t_{i}}>x, N(m) \geq \bar{N}\right) \\
& =\operatorname{Pr}\left(\sum_{i=1}^{N(m)} M_{t_{i}}>x \mid N(m) \geq \bar{N}\right) \operatorname{Pr}(N(m) \geq \bar{N}) \\
& >(1-y) \frac{\delta}{2}, \text { (using equations (28)and (29)). }
\end{aligned}
$$

The above means that for any given positive integer $x$ and for any given positive $y<1$, there exists an integer $\bar{m}^{\prime}=\max \left(m^{\prime}, \bar{m}\right)$ such that for $m>\bar{m}^{\prime}$,

$$
\operatorname{Pr}\left(\sum_{i=1}^{N(m)} M_{t_{i}}>x\right)>(1-y) \frac{\delta}{2}>0
$$


This further implies that

$$
\operatorname{Pr}\left(\sum_{i=1}^{\infty} M_{t_{i}}=\infty\right)>0 .
$$

This means that with a strictly positive probability the number of M-firms goes to infinity.

Now, if $M_{t_{i}}=1$, then the firm that enters at time $t_{i}$, where $h_{t_{i}}=1$, is a $M$-firm. Consider this $M$-firm. When $h_{t_{i}}=1$, this implies that at time $t_{i}-1, \widetilde{\widehat{P}}_{t_{i}-1}$ is above $\underline{\widetilde{c}}^{*}+\alpha \underline{\widetilde{q}}^{*}+\widetilde{\bar{\beta}} k+\frac{\epsilon^{\prime}}{\bar{A}}$. This, together with the property that for a $M$-firm $\underline{\widetilde{c}}^{*}+\frac{\epsilon^{\prime}}{\bar{A}}>\widetilde{c}_{\alpha}^{M}\left(\alpha q^{M}\right)$, $\widetilde{q}^{M} \leq \underline{\widetilde{q}}^{*}$, implies that

$$
\begin{aligned}
\widetilde{p}_{t_{i}}^{t_{i}}\left(\alpha q^{t_{i}}\right) \underset{q^{t_{i}=q^{M^{\prime}}}}{\mid}= & \widetilde{\widehat{P}}_{t-1}-\alpha \widetilde{q}^{M} \\
& >\widetilde{\widetilde{c}}^{*}+\alpha\left(\underline{\widetilde{q}}^{*}-\widetilde{q}^{M}\right)+\widetilde{\bar{\beta}} k+\frac{\epsilon^{\prime}}{\bar{A}} \\
& >\widetilde{c}_{\alpha}^{M}\left(\alpha q^{M}\right)+\widetilde{\beta}^{M} k .
\end{aligned}
$$

This further implies that $p_{t_{i}}^{t_{i}}\left(\alpha q^{M}\right)>c_{\alpha}^{t_{i}}\left(\alpha q^{M}\right)+\beta^{t_{i}} k$. This means that this $M$-firm's per unit revenue at its entry period ( which is $p_{t_{i}}^{t_{i}}\left(\alpha q^{M}\right)$ ) exceeds its per unit cost at its entry period (which is $c_{\alpha}^{t_{i}}\left(\alpha q^{M}\right)+\beta^{t_{i}} k$ ). Hence, this $M$-firm makes a strictly positive profit in its entry time period and it continues to produce in time period $t_{i}+1$. Lemma 1 implies that for this $k$ and $\epsilon^{\prime}$ and for any $\alpha<\bar{\alpha}$, this $M$-firm in any subsequent time periods has its product price greater than per unit cost (which is no more than $\underline{c}^{*}+\epsilon^{\prime}$ ). In other words, this $M$-firm makes a strictly positive profit in any subsequent time period after its entry. Therefore, this $M$-firm never exits the economy. Equation (30) implies that with a strictly positive probability there is an infinite number of such $M$-firms in the economy. Since those $M$-firms never exit the economy and since each individual $M$-firm produces at least $\alpha \underline{Q}$, the presence of the infinite number of such $M$-firms would drive 
the price for each of the producing firms, say firm $i$, below $\frac{c^{*} A^{i}}{\bar{A}}+a^{i} \alpha\left(Q_{i}^{*}-Q^{i}\right)+\epsilon^{\prime}$ with a strictly positive probability. This contradicts the result in Lemma 1. Therefore, equation (23) follows.

Since $\widetilde{p}_{t}^{i}\left(\alpha q^{i}\right)=\widetilde{\widehat{P}}_{t-1}-\alpha \widetilde{q}^{i}+b^{i} \alpha q^{i}-b^{t} \alpha q^{t}$ and since from the proof of Lemma 1, $b^{i} \alpha q^{i} \leq \bar{b} \alpha \bar{q} \leq \frac{\epsilon^{\prime}}{\underline{A}}$, equation (23) further implies that with probability 1 the following occurs: for this $k$ and $\epsilon^{\prime}<\frac{A \widetilde{A} k}{2}$ and for any $\alpha<\bar{\alpha}$, there must exist a time period, say $\tau\left(\epsilon^{\prime}, q, k, \alpha\right)$, such that for all $t>\tau\left(\epsilon^{\prime}, q, k, \alpha\right)$, for all firms $i \in \bar{S}_{t}=\{t\} \cup S_{t-1}$,

$$
\begin{aligned}
\widetilde{p}_{t}^{i}\left(\alpha q^{i}\right) & \leq \widetilde{\underline{c}}^{*}+\alpha \underline{q}^{*}+\widetilde{\bar{\beta}} k+\frac{\epsilon^{\prime}}{\bar{A}}-\alpha \widetilde{q}^{i}+b^{i} \alpha q^{i}-b^{t} \alpha q^{t} \\
& <\widetilde{\widetilde{c}}^{*}+\alpha\left(\underline{\widetilde{q}}^{*}-\widetilde{q}^{i}\right)+\widetilde{\bar{\beta}} k+\frac{\epsilon^{\prime}}{\overline{\bar{A}}}+\frac{\epsilon^{\prime}}{\frac{A}{\bar{A}^{\prime}}} \\
& \leq \widetilde{\widetilde{c}}^{*}+\alpha\left(\widetilde{q}_{i}^{*}-\widetilde{q}^{i}\right)+\widetilde{\widetilde{\beta}} k+\frac{\epsilon^{\prime}}{\bar{A}}+\frac{\frac{A}{\underline{A}}}{}
\end{aligned}
$$

Therefore, Lemma 2 is proven.

The results in Theorem are directly established by bringing together the results in Lemma 1 and 2 along with shrinking of the average entry cost $k$.

Proof of Theorem 1: (i(a)) Using Lemma 1 and Lemma 2, it follows that with probability 1, the following occurs: for any given $k$, for any given positive $\epsilon^{\prime}<\frac{A \underline{A} \widetilde{\beta} k}{2}$, there exists an $\bar{\alpha}$ such that, for $\alpha<\bar{\alpha}$, there exists a time period $\tau(\epsilon, Q, \alpha, k)$ such that for $t>\tau\left(\epsilon^{\prime}, Q, \alpha, k\right)$,

$$
\begin{gathered}
\underline{c}^{*} \frac{A^{i}}{\bar{A}}+a^{i} \alpha\left(Q_{i}^{*}-Q^{i}\right)+\epsilon^{\prime}<P_{t}^{i}\left(\alpha Q^{i}\right)<\underline{c}^{*} \frac{A^{i}}{\bar{A}}+a^{i} \alpha\left(Q_{i}^{*}-Q^{i}\right)+\frac{\overline{\beta A}}{\underline{A}} k+\epsilon^{\prime}+\frac{\bar{A}}{\underline{A}} \epsilon^{\prime}, \\
\text { for all } i \in \bar{S}_{t}=\{t\} \cup S_{t-1} .
\end{gathered}
$$

Define $\bar{k}=\frac{\underline{A}}{\overline{\beta A}} \epsilon^{\prime}$ and $\epsilon=\epsilon^{\prime}\left(2+\frac{\bar{A}}{\underline{A}}\right)$. Then, it follows that with probability 1 , the following occurs: for any given positive $\epsilon$, there exist positive numbers $\bar{k}$ and $\bar{\alpha}$ such 
that, for $\frac{2 \bar{A} \epsilon}{\underline{\beta}(2 \underline{A}+\bar{A})}<k<\bar{k}$ and for $\alpha<\bar{\alpha}$, there exists a time period $\tau(\epsilon, Q, \alpha, k)$ such that for $t>\tau(\epsilon, Q, \alpha, k)$,

$$
\frac{\underline{c}^{*} A^{i}}{\bar{A}}+a^{i} \alpha\left(Q_{i}^{*}-Q^{i}\right)<P_{t}^{i}\left(\alpha Q^{i}\right)<\frac{\underline{c}^{*} A^{i}}{\bar{A}}+a^{i} \alpha\left(Q_{i}^{*}-Q^{i}\right)+\epsilon, \text { for all } i \in \bar{S}_{t} .
$$

Since $\tau(\epsilon, Q, \alpha, k)$ depends on the entire sample path $Q=\left(Q^{1}, Q^{2}, \ldots\right)$, and not on the distribution function $F(\cdot)$, from which the $Q^{1}, Q^{2}, \ldots$, are drawn, perhaps, for experimentation purposes, it is of more interest to know from what time period and on that the price for each of the remaining firms, say firm $i$, is lying outside the interval $\left(\frac{\underline{c}^{*} A^{i}}{\bar{A}}+a^{i} \alpha\left(Q_{i}^{*}-Q^{i}\right), \frac{\underline{c}^{*} A^{i}}{\bar{A}}+a^{i} \alpha\left(Q_{i}^{*}-Q^{i}\right)+\epsilon\right)$ with a certain given probability. This can be done by applying to equation (31) the fact that almost sure convergence implies convergence in probability. In other words, this results in Part (i(a)) of Theorem 1.

(i(b)) Lemma 1 shows that for any given $k$, for any given positive $\epsilon^{\prime}<\frac{A \widetilde{\beta} k}{2}$, there exists an $\bar{\alpha}$ such that for $\alpha<\bar{\alpha}$, at any time period $t$, where $t=1,2, \ldots$, for $i \in \bar{S}_{t}=\{t\} \cup S_{t-1}$,

$$
\widetilde{p}_{t}^{i}\left(\alpha q^{i}\right)>\underline{\widetilde{c}}^{*}+\alpha\left(\widetilde{q}_{i}^{*}-\widetilde{q}^{i}\right)+\frac{\epsilon^{\prime}}{\underline{A}} .
$$

With $\frac{c_{i}^{*}}{A^{i}}<\frac{\underline{c}^{*}}{\bar{A}}+\frac{\epsilon}{2 \underline{A}+\bar{A}}$ and since $\epsilon^{\prime}=\left(\frac{\underline{A}}{2 \underline{A}+\bar{A}}\right) \epsilon$, then $\widetilde{c}_{i}^{*}+\alpha\left(\widetilde{q}_{i}^{*}-\widetilde{q}^{i}\right)<\widetilde{p}_{t}^{i}\left(\alpha q^{i}\right)$. In the original notation,

$$
c_{i}^{*}+a^{i} \alpha\left(Q_{i}^{*}-Q^{i}\right)<P_{t}^{i}\left(\alpha Q^{i}\right) .
$$

Furthermore, since $\underline{c}^{*} \frac{A^{i}}{\bar{A}} \leq c_{i}^{*}$, Part (i(a)) of Theorem 1 implies that for any $\alpha<\bar{\alpha}$ and for $\frac{2 \bar{A} \epsilon}{\underline{\beta}(2 \underline{A}+\bar{A})}<k<\bar{k}$, there exists a time period $\tau(\epsilon, \eta, \alpha, k)$ such that, for all $t>\tau(\epsilon, \eta, \alpha, k)$,

$$
\operatorname{Pr}\left(P_{t}^{i}\left(\alpha Q^{i}\right)<c_{i}^{*}+a^{i} \alpha\left(Q_{i}^{*}-Q^{i}\right)+\epsilon \text {, for all } i \in \bar{S}_{t} .\right)>1-\eta \text {. }
$$


Combining equations (32) and (33) along with the fact $\frac{c_{i}^{*}}{A^{i}} \geq \frac{c^{*}}{\bar{A}}$ gives the results of Part (i(b)) of Theorem.

(ii) The result in Part (i(a)) of Theorem 1 implies that for any given positive numbers $\epsilon$ and $\eta \in(0,1)$, there exist positive numbers $\bar{\alpha}$ and $\bar{k}$ such that, for any $\alpha<\bar{\alpha}$, for $\frac{2 \bar{A} \epsilon}{\underline{\beta}(2 \underline{A}+\bar{A})}<k<\bar{k}$, there exists a time period $\tau(\epsilon, \eta, \alpha, k)$ such that for all $t>\tau(\epsilon, \eta, \alpha, k)$,

$$
\operatorname{Pr}\left(\underline{\widetilde{c}}^{*}<\widetilde{p}_{t}^{i}\left(\alpha q^{i}\right)-\alpha\left(\widetilde{q}_{i}^{*}-\widetilde{q}^{i}\right)<\underline{\widetilde{c}}^{*}+\frac{\epsilon}{\bar{A}} \text {, for all } i \in \bar{S}_{t} .\right)>1-\eta
$$

For surviving firms, $i \in S_{t}$,

$$
\widetilde{p}_{t}^{i}\left(\alpha q^{i}\right)-\widetilde{c}_{\alpha}^{i}\left(\alpha q^{i}\right) \geq 0
$$

But, since $c_{\alpha}^{i}\left(\alpha q_{i}^{*}\right)=c_{i}^{*},\left.\frac{\partial c_{\alpha}^{i}\left(\alpha q^{i}\right)}{\partial\left(\alpha q^{i}\right)}\right|_{\alpha q^{i}=\alpha q_{i}^{*}}=-1$, and $\frac{\partial^{2} c_{\alpha}^{i}\left(\alpha q^{i}\right)}{\partial\left(\alpha q^{i}\right)^{2}}>0$, for any $i=1,2, \ldots$,

$$
\widetilde{c}_{\alpha}^{i}\left(\alpha q^{i}\right) \geq \widetilde{c}_{i}^{*}+\alpha\left(\widetilde{q}_{i}^{*}-\widetilde{q}^{i}\right)
$$

Combining equations (35) and (36), for all surviving firms $i \in S_{t}$,

$$
\widetilde{p}_{t}^{i}\left(\alpha q^{i}\right)-\alpha\left(\widetilde{q}_{i}^{*}-\widetilde{q}^{i}\right) \geq \widetilde{c}_{i}^{*}
$$

Since surviving firms at time $t$ must also be producing firms at time $t$ and since $\underline{\widetilde{c}}^{*} \leq \widetilde{c}_{i}^{*}$, therefore, combining equations (34) and (37), for any given positive numbers $\epsilon$ and $\eta \in(0,1)$, there exist positive numbers $\bar{\alpha}$ and $\bar{k}$ such that, for any $\alpha<\bar{\alpha}$ and for $\frac{2 \bar{A} \epsilon}{\underline{\beta}(2 \underline{A}+\bar{A})}<k<\bar{k}$, there exists a time period $\tau(\epsilon, \eta, \alpha, k)$ such that for all $t>\tau(\epsilon, \eta, \alpha, k)$,

$$
\operatorname{Pr}\left(\widetilde{c}_{i}^{*} \leq \widetilde{p}_{t}^{i}\left(\alpha q^{i}\right)-\alpha\left(\widetilde{q}_{i}^{*}-\widetilde{q}^{i}\right)<\widetilde{c}_{i}^{*}+\frac{\epsilon}{\bar{A}} \text { and } \underline{\widetilde{c}}^{*} \leq \widetilde{c}_{i}^{*}<\underline{\underline{c}}^{*}+\frac{\epsilon}{\bar{A}} \text { for } i \in S_{t}\right)>1-\eta \text {. }
$$


By equations (35) and (36), $\widetilde{c}_{i}^{*} \leq \widetilde{c}_{\alpha}^{i}\left(\alpha q^{i}\right)-\alpha\left(\widetilde{q}_{i}^{*}-\widetilde{q}^{i}\right) \leq \widetilde{p}_{t}^{i}\left(\alpha q^{i}\right)-\alpha\left(\widetilde{q}_{i}^{*}-\widetilde{q}^{i}\right)$ and since $\underline{\widetilde{c}}^{*} \leq \widetilde{c}_{i}^{*}$, therefore,

$$
\operatorname{Pr}\left(\widetilde{c}_{i}^{*} \leq \widetilde{c}_{\alpha}^{i}\left(\alpha q^{i}\right)-\alpha\left(\widetilde{q}_{i}^{*}-\widetilde{q}^{i}\right)<\widetilde{c}_{i}^{*}+\frac{\epsilon}{\bar{A}} \text { and } \underline{\widetilde{c}}^{*} \leq \widetilde{c}_{i}^{*}<\underline{\underline{c}}^{*}+\frac{\epsilon}{\bar{A}} \text { for } i \in S_{t}\right)>1-\eta \text {. }
$$

Finally, in terms of the original notation, this implies that, for any given positive numbers $\epsilon$ and $\eta \in(0,1)$, there exist positive numbers $\bar{\alpha}$ and $\bar{k}$ such that, for any $\alpha<\bar{\alpha}$ and for $\frac{2 \bar{A} \epsilon}{\underline{\beta}(2 \underline{A}+\bar{A})}<k<\bar{k}$, there exists a time period $\tau(\epsilon, \eta, \alpha, k)$ such that for all $t>\tau(\epsilon, \eta, \alpha, k)$,

$$
\operatorname{Pr}\left(\begin{array}{c}
c_{i}^{*}+a^{i} \alpha\left(Q_{i}^{*}-Q^{i}\right) \leq C_{\alpha}^{i}\left(\alpha Q^{i}\right)<c_{i}^{*}+a^{i} \alpha\left(Q_{i}^{*}-Q^{i}\right)+\epsilon \\
\text { and } \frac{c_{i}^{*}}{A^{i}}<\frac{c^{*}}{\bar{A}}+\frac{\epsilon}{\bar{A}} \text {, for all } i \in S_{t}
\end{array}\right)>1-\eta
$$

(iii) The result in Part (i(a)) of Theorem 1 implies that for any given positive numbers $\epsilon$ and $\eta \in(0,1)$, there exist positive numbers $\bar{\alpha}$ and $\bar{k}$ such that, for any $\alpha<\bar{\alpha}$, for $\frac{2 \bar{A} \epsilon}{\underline{\beta}(2 \underline{A}+\bar{A})}<k<\bar{k}$, there exists a time period $\tau(\epsilon, \eta, \alpha, k)$ such that for all $t>\tau(\epsilon, \eta, \alpha, k)$,

$$
\operatorname{Pr}\left(\underline{\widetilde{c}}^{*}<\widetilde{p}_{t}^{i}\left(\alpha q^{i}\right)-\alpha\left(\widetilde{q}_{i}^{*}-\widetilde{q}^{i}\right)<\underline{\widetilde{c}}^{*}+\frac{\epsilon}{\bar{A}} \text {, for all } i \in \bar{S}_{t} .\right)>1-\eta
$$

Consider the following two cases:

Case 1: Suppose $C_{\alpha}^{t}\left(\alpha Q^{t}\right) \notin\left[c_{t}^{*}+a^{t} \alpha\left(Q_{t}^{*}-Q^{t}\right), c_{t}^{*}+a^{t} \alpha\left(Q_{t}^{*}-Q^{t}\right)+\epsilon\right)$. This implies

$$
\widetilde{c}_{\alpha}^{t}\left(\alpha q^{t}\right) \notin\left[\widetilde{c}_{t}^{*}+\alpha\left(\widetilde{q}_{t}^{*}-\widetilde{q}^{t}\right), \widetilde{c}_{t}^{*}+\alpha\left(\widetilde{q}_{t}^{*}-\widetilde{q}^{t}\right)+\frac{\epsilon}{A^{t}}\right) .
$$

Since $c_{\alpha}^{i}\left(\alpha q_{i}^{*}\right)=c_{i}^{*}, \frac{\partial c_{\alpha}^{i}\left(\alpha q^{i}\right)}{\partial\left(\alpha q^{i}\right)} \underset{\alpha q^{i}=\alpha q_{i}^{*}}{\mid}=-1$, and $\frac{\partial^{2} c_{\alpha}^{i}\left(\alpha q^{i}\right)}{\partial\left(\alpha q^{i}\right)^{2}}>0$ for any $i=1,2, \ldots$, this means 
that

$$
\widetilde{c}_{\alpha}^{t}\left(\alpha q^{t}\right) \geq \widetilde{c}_{t}^{*}+\alpha\left(\widetilde{q}_{t}^{*}-\widetilde{q}^{t}\right)+\frac{\epsilon}{A^{t}} .
$$

Since $\widetilde{\widetilde{c}}^{*} \leq \widetilde{c}_{t}^{*}$ and $A^{t} \leq \bar{A}$, equations (38) and (39) imply that

$$
\operatorname{Pr}\left(\widetilde{p}_{t}^{t}\left(\alpha q^{t}\right)-\alpha\left(\widetilde{q}_{t}^{*}-\widetilde{q}^{t}\right)<\widetilde{c}_{\alpha}^{t}\left(\alpha q^{t}\right)-\alpha\left(\widetilde{q}_{t}^{*}-\widetilde{q}^{t}\right)\right)>1-\eta .
$$

This in turn implies that

$$
\operatorname{Pr}\left(\widetilde{p}_{t}^{t}\left(\alpha q^{t}\right)-\widetilde{c}_{\alpha}^{t}\left(\alpha q^{t}\right)<0\right)>1-\eta
$$

Furthermore, since $\widetilde{p}_{t}^{t}\left(\alpha q^{t}\right)-\widetilde{c}_{\alpha}^{t}\left(\alpha q^{t}\right)-\widetilde{\beta}^{t} k<\widetilde{p}_{t}^{t}\left(\alpha q^{t}\right)-\widetilde{c}_{\alpha}^{t}\left(\alpha q^{t}\right)$, then

$$
\operatorname{Pr}\left(\widetilde{p}_{t}^{t}\left(\alpha q^{t}\right)-\widetilde{c}_{\alpha}^{t}\left(\alpha q^{t}\right)-\widetilde{\beta}^{t} k<0\right)>1-\eta
$$

Thus,

$$
\operatorname{Pr}\left(P_{t}^{t}\left(\alpha Q^{t}\right)-C_{\alpha}^{t}\left(\alpha Q^{t}\right)-\beta^{t} k<0\right)>1-\eta .
$$

Case 2: Suppose $\frac{c_{t}^{*}}{A^{t}} \geq \frac{\underline{c}^{*}}{\bar{A}}+\frac{\epsilon}{\bar{A}}$ and $C_{\alpha}^{t}\left(\alpha Q^{t}\right) \in\left[c_{t}{ }^{*}+a^{t} \alpha\left(Q_{t}^{*}-Q^{t}\right), c_{t}{ }^{*}+a^{t} \alpha\left(Q_{t}^{*}-Q^{t}\right)\right.$ $+\epsilon)$. This means that

$$
\widetilde{c}_{\alpha}^{t}\left(\alpha q^{t}\right) \geq \widetilde{c}_{t}^{*}+\alpha\left(\widetilde{q}_{t}^{*}-\widetilde{q}^{t}\right)
$$

If equation (40) is subtracted from equation (38), then for any given positive numbers $\epsilon$ and $\eta \in(0,1)$, there exist positive numbers $\bar{\alpha}$ and $\bar{k}$ such that, for any $\alpha<\bar{\alpha}$ and for $\frac{2 \bar{A} \epsilon}{\underline{\beta}(2 \underline{A}+\bar{A})}<k<\bar{k}$, there exists a time period $\tau(\epsilon, \eta, \alpha, k)$ such that for all $t>\tau(\epsilon, \eta, \alpha, k)$,

$$
\operatorname{Pr}\left(\widetilde{p}_{t}^{t}\left(\alpha q^{t}\right)-\widetilde{c}_{\alpha}^{t}\left(\alpha q^{t}\right)<\underline{\widetilde{c}}^{*}-\widetilde{c}_{t}^{*}+\frac{\epsilon}{\bar{A}}\right)>1-\eta
$$


Since $\frac{c_{t}^{*}}{A^{t}} \geq \frac{\underline{c}^{*}}{\overline{\bar{A}}}+\frac{\epsilon}{\bar{A}}$, it follows that $\underline{\widetilde{c}}^{*}-\widetilde{c}_{t}^{*}+\frac{\epsilon}{\bar{A}} \leq 0$, then

$$
\operatorname{Pr}\left(\widetilde{p}_{t}^{t}\left(\alpha q^{t}\right)-\widetilde{c}_{\alpha}^{t}\left(\alpha q^{t}\right)<0\right)>1-\eta
$$

In turn, since $\widetilde{p}_{t}^{t}\left(\alpha q^{t}\right)-\widetilde{c}_{\alpha}^{t}\left(\alpha q^{t}\right)-\widetilde{\beta}^{t} k<\widetilde{p}_{t}^{t}\left(\alpha q^{t}\right)-\widetilde{c}_{\alpha}^{t}\left(\alpha q^{t}\right)$, it follows that

$$
\operatorname{Pr}\left(\widetilde{p}_{t}^{t}\left(\alpha q^{t}\right)-\widetilde{c}_{\alpha}^{t}\left(\alpha q^{t}\right)-\widetilde{\beta}^{t} k<0\right)>1-\eta
$$

Thus,

$$
\operatorname{Pr}\left(P_{t}^{t}\left(\alpha Q^{t}\right)-C_{\alpha}^{t}\left(\alpha Q^{t}\right)-\beta^{t} k<0\right)>1-\eta
$$

The result in Part (iii) is proven.

\section{Appendix C}

\section{Proposition 4}

If

$$
\operatorname{Pr}\left(\sum_{i=1}^{N(m)} M_{t_{i}}>x \mid N(m)=r\right)>1-y, \text { for } r \geq \bar{N}
$$

then

$$
\operatorname{Pr}\left(\sum_{i=1}^{N(m)} M_{t_{i}}>x \mid N(m) \geq \bar{N}\right)>1-y
$$


Proof.

$$
\begin{aligned}
& \operatorname{Pr}\left(\sum_{i=1}^{N(m)} M_{t_{i}}>x \mid N(m) \geq \bar{N}\right) \\
& \quad=\frac{\operatorname{Pr}\left(\sum_{i=1}^{N(m)} M_{t_{i}}>x,(N(m)=\bar{N}, \text { or, } N(m)=\bar{N}+1, \text { or, }, \ldots, \text { or }, N(m)=m)\right)}{\operatorname{Pr}(N(m)=\bar{N}, \text { or, } N(m)=\bar{N}+1, \text { or }, \ldots, \text { or }, N(m)=m)} \\
& \quad=\sum_{r=\bar{N}}^{m} \frac{\operatorname{Pr}\left(\sum_{i=1}^{N(m)} M_{t_{i}}>x, N(m)=r\right)}{\operatorname{Pr}(N(m)=\bar{N}, \text { or }, N(m)=\bar{N}+1, \text { or, }, \ldots, \text { or }, N(m)=m)} \\
& \quad=\sum_{r=\bar{N}}^{m}\left(\frac{\operatorname{Pr}\left(\sum_{i=1}^{N(m)} M_{t_{i}}>x, N(m)=r\right)}{\operatorname{Pr}(N(m)=r)} \frac{\operatorname{Pr}(N(m)=r)}{\operatorname{Pr}(N(m)=\bar{N}, \text { or, } N(m)=\bar{N}+1, \text { or, }, \ldots, \text { or }, N(m)=m)}\right) \\
&>(1-y) \sum_{r=\bar{N}}^{m} \frac{\operatorname{Pr}(N(m)=r)}{\operatorname{Pr}(N(m)=\bar{N}, \text { or }, N(m)=\bar{N}+1, \text { or, }, \ldots, \text { or }, N(m)=m)} \text { using eq. (41)) } \\
&>(1-y) .
\end{aligned}
$$

\section{References}

[1] Alchian, A., (1950) Uncertainty, Evolution and Economic Theory, Journal of Political Economy, 58, 211-222.

[2] Andrews, P.W.S., (1949) Manufacturing Business, London: Macmillan.

[3] Arrow, K.J., (1986) Rationality of Self and Others in an Economic System, Journal of Business, 59, 4, pt. 2, s385-s399.

[4] Blume, L. E. and D. Easley, (2002) Optimality and Natural Selection in Markets, Journal of Economic Theory, 107(1), 95-135.

[5] Baumol, W.J., (1959) Business Behavior, Value and Growth, New York: Macmillan. 
[6] Chamberlin, E.H., (1933) The Theory of Monopolistic Competition, Cambridge, MA.: Harvard University Press, 8th ed. (1969).

[7] Cyert, R.M. and J.G. March, (1963) A Behavioral Theory of the Firm, Englewood Cliffs, NJ.:Prentice-Hall.

[8] Dutta, P. and R. Radner, (1999) Profit Maximization and the Market Selection Hypothesis, Review of Economic Studies, 66, 769-798.

[9] Enke, S., (1951) On Maximizing Profits: A Distinction Between Chamberlin and Robinson, American Economic Review, 41, 566-578.

[10] Friedman, M., "Essays in Positive Economics," University of Chicago Press, Chicago, 1953.

[11] Luo, G.Y., (1995) Evolution and Market Competition, Journal of Economic Theory, $67,223-250$.

[12] Luo, G.Y., (2007) Irrationality and Monopolistic Competition: An Evolutionary Approach, European Economic Review (2008), doi: 10.1016/j.euroecorev.2008.09.001.

[13] Nelson, R. and S. Winter, (1982) An Evolutionary Theory of Economic Change, Cambridge, MA: Harvard University Press.

[14] Novshek, W. (1985) On the Existence of Cournot Equilibrium, Review of Economic Studies, 52, 85-98.

[15] Pratten, C. F. (1971). Economies of Scale in Manufacturing Industry. Cambridge: Cambridge University Press. 
[16] Robinson, J., (1933) The Economics of Imperfect Competition, London: Macmillan.

[17] Robson, A., (1990) Stackleberg and Marshall, American Economic Review, 80, $69-82$.

[18] Scherer, F. M. (1973) The Determinants of Industry Plant Sizes in Six Nations, Review of Economics and Statistics 55(2): 135-175.

[19] Simon, H., (1979) Rational Decision Making in Business Organizations, American Economic Review, 69, 493-513.

[20] Weiss, Leonard W. (1963) Factors in Changing Concentration, Review of Economics and Statistics 45(1): 70-77.

[21] Weiss, Leonard W. (1976) Optimal Plant Scale and the Extent of Suboptimal Capacity, In R. T. Masson and P. D. Qualls, eds. Essays on Industrial Organization in Honor of Joe S. Bain, Cambridge, MA: Ballinger, pp. 126-134.

[22] Williamson, O.E. (1964) The Economics of Discretionary Behavior: Managerial Objectives in a Theory of the Firm, Englewood Cliffs, NJ: PrenticeHall.

[23] Winter, S., (1964) Economic Natural Selection and the Theory of the Firm, Yale Economic Essays, 4, 225-272.

[24] Winter, S., (1971) Satisficing, Selection and the Innovating Remnant, Quarterly Journal of Economics, 85, 237-261. 